\title{
Eugénio Tavares: Um intelectual a serviço de seu povo
}

\author{
Genivaldo Rodrigues Sobrinho ${ }^{1}$
}

\begin{abstract}
RESUMO: A produção literária cabo-verdiana do século XIX foi influenciada pelos modelos europeus, tendo suas bases estruturantes, conforme anunciadas na revista Claridade, já discutidas por Eugénio Tavares. A produção de Tavares, questionadora dos rumos não somente da literatura, mas também de Cabo Verde como nação independente, deu-se no primeiro período da literatura cabo-verdiana. O principal objetivo deste artigo é fazer uma apresentação sobre Eugénio Tavares, e sua produção, como um intelectual preocupado com os problemas de seu país.
\end{abstract}

ABSTRACT: The nineteenth century Cape Verdian literary production was under the influence of European patterns. The bases on which this literature had been structured, as announced on Claridade magazine, was already discussed by Eugénio Tavares, which wrote in early period of Cape Verdean literature. His production questions not only the literature, but also Cape Verde as an independent nation. The main purpose of this paper is to introduce Eugénio Tavares, and his production, as an intellectual worried about the problems of his country.

PALAVRAS-CHAVE: Literatura cabo-verdiana, Eugénio Tavares, intelectual. KEYWORDS: Cape Verdean Literature, Eugénio Tavares, intellectual.

\section{Alguns Dados Biográficos}

Eugénio de Paula Tavares nasceu na Ilha Brava, em 18 de outubro de 1867 e faleceu aos 63 anos, em 01 de junho de 1930, na mesma ilha. Seus pais foram Francisco de Paula Tavares e Eugénia Nozoliny Tavares. Casou-se com Guiomar Leça Tavares. O casal não teve filhos, fato que ambos sempre lamentaram.

Mesmo não tendo freqüentado o Liceu de São Nicolau nem tido a oportunidade de estudar em qualquer outro estabelecimento de ensino fora de seu país, Eugénio Tavares era possuidor de uma apurada formação cultural que viria a se refletir em sua produção escrita. Apesar de ser autodidata em sua formação cultural, como jornalista e prosador, Eugénio Tavares dominou o cenário cabo-verdiano nas primeiras décadas do século XX. A este respeito, vejamos o que nos dizem Carlota e Viriato de Barros em texto de uma conferência proferida na cidade Lisboa, em 2005:

1 Doutorando em Estudos Comparados de Literaturas de Língua Portuguesa, FFLCH- USP. Pesquisa: Interfaces de Eugénio Tavares no Exílio. E-mail: genivaldor@hotmail.com 
A formação de Eugénio Tavares fez-se no excelente ambiente em que cresceu, entre gente de cultura e conhecimento, a cujas bibliotecas tinha acesso constante e que constituíam para ele autênticos santuários pessoais de estudo. Em todas as ilhas havia, aliás, os chamados "gabinetes de estudo" que respondiam a essa intensa ânsia de saber, a essa sede de leitura, só mitigada após os calculados períodos de espera, ao sabor do calendário de chegada dos navios, dos "vapores", que chegavam a Cabo Verde, trazendo jornais e livros de toda a espécie, criando uma dependência-quasevício nos leitores das ilhas. Esse era o ambiente em que cresceu, viveu e se formou Eugénio Tavares [...]. Mas foi sobretudo aluno do seu povo, da sua terra, da sua ilha, da cultura do seu povo que amou sem condições, sofrendo as suas dores, lutando as suas lutas, sentindo como própria as suas revoltas, porque doutra forma não podia ser, mas vivendo também os seus amores e as dores de quem ama com essa intensidade que se sente nos seus poemas ${ }^{2}$.

Sabe-se, portanto, que Eugénio Tavares - apesar de todas as limitações e dificuldades - superou os obstáculos em busca de seu desenvolvimento intelectual. Carlota e Viriato ressaltam, ainda, o talento deste escritor cabo-verdiano, que foi descoberto pelo poeta bravense Luiz Medina de Vasconcelos. Este publicou um poema de Eugénio Tavares no Almanaque de Lembranças Luso-Brasileira (sic), enfatizando sua qualidade, inclusive o conhecimento da língua e dos códigos de versificação. Ao lado desses atributos, também se destacou a devoção à justiça social deste autor face ao descaso do Governo central, bem como sua militância na causa republicana pela justiça social. No jornalismo, com seu talento e mestria na linguagem, denuncia com veemência os graves problemas sociais de sua terra.

A revelação do talento precoce de Eugénio Tavares foi fundamental para que o seu caráter combativo, questionador, voltado para seu país e sua gente se moldasse e se fortalecesse para o prosseguimento de seus embates em favor das conquistas políticas e sociais imprescindíveis, sem o apelo fácil ao meramente panfletário.

Exerceu por pouco tempo o cargo oficial de Recebedor de Finanças. Mesmo num período curto, a sua determinação em combater as injustiças sociais foi motivo para o surgimento de inimigos nas esferas do poder. Fortes perseguições políticas são iniciadas. Seus inimigos usam dos meios mais baixos para o acusarem de desvio de dinheiro público. Sem outra opção, foge para os Estados Unidos da América a bordo de um navio, disfarçado de mulher, vindo a se fixar na cidade de New Bedford, cidade emblemática da região da Nova Inglaterra - cidade-porto dos navios baleeiros - para onde rumavam muitos caboverdianos.

2 Disponível em: www.eugeniotavares.org. Acesso em 24/06/2005 às 21:46. 
Conta-se que Eugénio Tavares retornou em duas ou três ocasiões a Cabo Verde, clandestinamente. Ao ter o seu pedido para aguardar o julgamento da acusação de posse de dinheiro público, aceita, volta à Brava. No entanto, problemas financeiros o fazem viajar novamente aos Estados Unidos para garantir a sobrevivência dele e da família. Em 1910, regressa definitivamente ao seu país. Seu processo é julgado somente em 1921, e ele é absolvido. A população comemora com grande entusiasmo, sendo cumprimentado inclusive pelo governador colonial Maia Magalhães.

Em outubro de 1927, Eugénio Tavares é oficialmente homenageado pelo governador Guedes Vaz, na cidade de Mindelo. Guedes Vaz atesta em público a honradez e a integridade moral do poeta.

Três anos após, em 01 de junho de 1930, Eugénio Tavares morre fulminado por um ataque cardíaco enquanto almoçava com alguns de seus amigos mais próximos. Nas palavras do também poeta Artur Vieira, a morte de Nhô Eugénio, como os seus conterrâneos carinhosamente o chamavam, foi um desastre para a cultura cabo-verdiana.

Durante a despedida fúnebre do poeta, o caixão com o seu corpo percorre todas as ruas de Nova Sintra, cidade da Ilha Brava, acompanhado de chuva de pétalas de rosas e ao som de violinos e violões, que tocam uma de suas obras-prima: a morna Hora di Bai.

\section{O Exercício de um Intelectual}

O século XIX, como todo o período anterior da Literatura de Cabo Verde, é influenciado ou determinado, enquanto produção estética e literária, pelos modelos europeus. As bases em que se estruturam a nova fase da produção literária em Cabo Verde, anunciadas na revista Claridade, já eram discutidas e debatidas anteriormente por Eugénio Tavares desde o final do século XIX. Sua produção, questionadora dos rumos não só da Literatura como também de Cabo Verde como nação independente, deu-se no primeiro período da Literatura Cabo-Verdiana, ou seja, das origens até 1925, Período de Iniciação, conforme afirma Pires Laranjeira (1995, p. 180).

Lançando mão das "mornas", canções escritas em língua crioula, o autor enfoca questões de natureza política e social, na confluência de arte e sociedade. Nesse encontro, o autor introduz a forma popular. O texto engajado abre o debate sobre a necessidade da independência política, social e cultural de Cabo Verde. 
José António Nobre Marques Guimarães em O Nativismo em Eugénio Tavares (2005) nos diz que o fio condutor da ação política e jornalística do poeta, desde cedo, ergue-se contra a contratação de serviçais para São Tomé. Pois o trabalho pesado e muito mal remunerado era quase equivalente à escravidão. Este era destinado aos cabo-verdianos que se submetiam a ele em virtude do estado miserável em que viviam, uma vez que não tinham outra alternativa diante das sucessivas secas que assolavam o país causando um grande caos social. Havia um interesse por parte da administração colonial em se aproveitar desse cenário de calamidades, já que desta forma o governo português conseguia mão-deobra quase gratuita para o trabalho nas plantações de cacau em São Tomé.

Essas denúncias de exploração do povo aparecem em artigos publicados pela Revista de Cabo Verde, impressa e editada em Lisboa "[...] a fim de evitar a repressão directa das autoridades da colônia” (GUIMARÃES, 2005: p. 1). Nessa fase, o autor discute também a fragilidade educacional de sua terra e defende a necessidade de criação de escolas.

A postura engajada e contestadora de Eugénio Tavares o obriga a se exilar nos Estados Unidos em 1900. O exílio vai até 1910. Durante esse período, Eugénio Tavares amadurece política e intelectualmente por meio de alguns contatos estabelecidos com diversas " $[\ldots]$ correntes políticas empenhadas na emancipação dos oprimidos, com destaque para o pan-africanismo" (GUIMARÃES, 2005: p. 2). Já de volta a Cabo Verde, em 1911, o escritor torna mais enfático seu discurso em defesa dos direitos do povo cabo-verdiano.

Nos Estados Unidos, Eugénio Tavares cria o jornal A Alvorada, e, em agosto do mesmo ano, publica o artigo intitulado "Autonomia", manifestando-se contrário à ameaça de venda das colônias e à necessidade dos cabo-verdianos e demais povos estarem sujeitados à dominação portuguesa. Via, nesse momento, o imperativo de criação de um partido autônomo: "Portugueses-irmãos, sim: Portugueses-escravos, nunca. Havemos de ter o nosso Monroe: A África para os africanos" (TAVARES apud MONTEIRO, 1997: p. 70). Com essa afirmativa, o autor conclama a necessidade da liberdade de Cabo Verde ao mesmo tempo em que estende esse debate como realidade necessária a todas as colônias portuguesas: “[...] clamando a África para os africanos, este é o seu primeiro apelo à independência de Cabo Verde”. (FORTES, 2002: p. 02)

$\mathrm{Na}$ Voz de Cabo Verde, Eugénio Tavares continua a defesa intransigente do povo de seu país e discute a emigração dos cabo-verdianos para os Estados Unidos. Em carta escrita em junho de 1918, dirigida a D. Alexandre de Almeida, intitulada Noli me tangere, o autor 
pontua e analisa a emigração dos cabo-verdianos e suas conseqüências. Ao refletir sobre o processo emigratório, Eugénio Tavares consolida veementemente o discurso crítico, aponta os motivos que levam os cabo-verdianos a deixar seu país e ainda destaca os pontos positivos para aqueles que deixavam sua terra natal rumo à América:

$1^{\circ}[\ldots] \mathrm{O}$ caboverdiano ${ }^{3}$ não vai à América apenas à cata de alimento. $2^{\circ}[\ldots] \mathrm{O}$ caboverdiano, quando regressa [...] traz, não só "dollars", senão luzes; e apresenta, não só um exterior de civilizado, mas uma noção social por vezes mais justa que aquela que de outra parte lhe seria possível trazer. $3^{\circ}[\ldots]$ O caboverdiano, na América, modifica o seu modo de ser moral, erguendo-se de um absoluto anonimato social, a consciente elemento de progresso. $4^{\circ}[\ldots]$ Açacalado no contacto do grande povo americano, o caboverdiano aprende a encarar a vida por um prisma mais elevado; cria necessidades que lhe educam a vontade em lutas mais nobres, integra-se na civilização, já não se adaptando dentro da estreita exigência da cubata e da cachupa [...]. $5^{\circ}$ [...] Finalmente, o caboverdiano pertence, como todos nós sabemos, a esse número de homens cujas aspirações se não limitam à actividade mandibular. [...] Interromper a emigração caboverdiana, para os Estados Unidos, é muito simples de dizer ou de escrever, mas é de dificílima execução (TAVARES apud GUIMARÃES, 2005: p. 03).

Corsino Fortes (2002, p. 3) observa que a emigração é um fenômeno característico da vivência do homem no arquipélago. Eugénio Tavares discute que há dois tipos de emigração: a emigração desejada e espontânea, que ocorre no final do século XIX, e a emigração compulsória, ocorrida no início do século XX. A diferença entre as duas é a distinção do destino: na primeira fase, o cabo-verdiano vai em busca dos Estados Unidos da América; já na segunda, segue para Angola e São Tomé e Príncipe. A emigração do início do século XX tem como motivo "[...] o desespero de uma população que, flagelada pelas secas, desemprego, miséria e fome, é incitada pelas pressões administrativas a ir trabalhar mediante contratos de miséria que geralmente não são cumpridos" (TAVARES apud FORTES, 2002: p. 3).

Outra fase de publicação em periódicos é a década de 20. Em $O$ Manduco $n^{o} .11$, Eugénio Tavares publicou um texto em defesa e definição do crioulo, intitulado Língua de Pretos, em janeiro de 1924, no qual discorre sobre “[...] o carácter do povo caboverdiano [...]" e afirma que este está impresso "[...] na fonalidade dos seus dialectos, que variam de ilha para ilha como de ilha para ilha varia o perfil físico".

\footnotetext{
3 As grafias "caboverdiano" / "caboverdiana", "caboverdeano", "caboverdianidade” ocorre em citações e títulos neste texto. Todavia, a forma dicionarizada é "cabo-verdiano" e derivados. Daí a oscilação gráfica.
} 
A visão crítica de Eugénio Tavares define a "língua de pretos" como uma língua de branco mal ensinada aos pretos. São os mesmos pretos que amamentaram e cuidaram dos filhos desses brancos, “[...] e que lhes acalentaram os sonos da infância com as tristíssimas melopéias da saudade dos lares distantes e do sofrimento da escravidão" [...] (TAVARES apud MONTEIRO, 1997: p, 219). Há uma clara discussão da colonização que traz a escravidão como a mais grave ocorrência no contato entre brancos e negros, durante gerações. A língua do colonizador (branco) é assimilada, trazendo consigo as marcas históricas de sofrimento e as "[...] reminiscências bárbaras que eivaram da própria língua dos senhores" (Op. cit, p. 219).

É desse encontro, também presente na língua, que Eugénio Tavares entende esse processo como um documento da transformação de duas culturas, no ciclo histórico, como também do próprio idioma:

[...] Aligeirando razões, permita-se-me a seguinte conclusão: o dialecto caboverdiano pode falar-se e grafar-se. Por muitos motivos, e, principalmente, porque constitui a documentação de uma transformação, digo, de uma das transformações felizes da língua portuguesa entre os povos coloniais ${ }^{4}$.

Um dos principais debates apresentados por Eugénio Tavares no jornal $O$ Manduco define uma trajetória de produção do jornalista e poeta que, desde a Revista de Cabo Verde vem tecendo o projeto mais político que literário que encontra como objetivo principal a independência de Cabo Verde. Eugénio Tavares se projeta como um dos primeiros intelectuais cabo-verdianos que, desde o final século XIX, consolida um discurso de ruptura política, visando à emancipação e melhores condições de vida para o povo de seu país.

\section{Referências bibliográficas}

BARROS, Carlota \& BARROS, Viriato. O amor em Eugénio Tavares. Disponível em: http://www.eugeniotavares.org/docs/pt/noticias/amor_em_eugenio_tavares.html. Acesso em: 14/06/2005, às 09:20.

FORTES, Corsino. Eugénio Tavares: um construtor do humanismo cabo-verdiano. Disponível em: http://www.humanismolatino.online.pt. Acesso em: 12/06/2005 às 20:15.

GUIMARÃES, José António Nobre Marques. O nativismo em Eugénio Tavares. Disponível em: $\mathrm{http}: / / \mathrm{www}$. eugeniotavares.org/docs/pt/noticias/nativismo_eugenio_tavares.html Acesso em 24/06/2005 às 21:55.

\footnotetext{
${ }^{4}$ Os trechos citados foram extraídos de: Marques, J. Nobre Guimarães. O nativismo em Eugénio Tavares Disponível em: http://www.eugeniotavares.org/docs/pt/noticias/nativismo_eugenio
} 
LARANJEIRA, Pires. Literaturas africanas de expressão portuguesa. Lisboa: Universidade Aberta, 1995.

MONTEIRO, Félix. Eugénio Tavares - pelos jornais... Praia: Instituto Caboverdeano do Livro e do Disco, 1997.

TAVARES, Eugénio. Mornas - cantigas crioulas. Luanda: Liga dos Amigos de Cabo Verde, 1969. 